\title{
Interações entre o uso dos pronomes demonstrativos e os gêneros feminino e masculino nas cartas de Júlio e Marina Mesquita
}

DOl: http://dx.doi.org/10.21165/el.v49i3.2636

\author{
Hélcius Batista Pereira'
}

\section{Resumo}

Este trabalho analisa a relação de interação entre a variação dos pronomes "este" e "esse" e as noções de "masculino" e "feminino" em cartas trocadas nas décadas de 1930 e 1940 entre Júlio Mesquita Filho e Marina Vieira de Carvalho Mesquita, membros da importante família Mesquita de São Paulo, proprietária de O Estado de S. Paulo. Nossa pesquisa é baseada na "terceira onda de sociolinguística" proposta por Eckert (2005) e Eckert e McConnell-Ginet (2010), que estudam a relação entre linguagem e categorias sociais, considerando estas últimas como construções não abstratas, pertinentes a uma "comunidade de prática" específica. Nossa análise evidenciou a adesão de Júlio e Marina ao processo de mudança do sistema demonstrativo do português brasileiro, caracterizado pela intensificação do uso do "esse", principalmente na endófora. As diferenças de uso entre os dois missivistas revelam maneiras pelas quais eles se engajaram pela linguagem como homem e mulher de seu tempo.

Palavras-chave: variação linguística; gêneros; comunidade de prática; História Social do português brasileiro.

1 Universidade Estadual de Maringá (UEM), Maringá, Paraná, Brasil; hbpereira@uem.br; https://orcid.org/0000-0002-5222-9267 


\title{
Interactions between the use of demonstrative pronouns and the genres female and male in the letters of Júlio and Marina Mesquita
}

\begin{abstract}
This paper analyzes the interactions between the variation of pronouns "este" and "esse" and the notions of "masculine" and "feminine" in letters exchanged in the 1930s and 1940s by Júlio Mesquita Filho and Marina Vieira de Carvalho Mesquita, members of the Mesquita family from São Paulo City, owner of the newspaper called "O Estado de S. Paulo". Our research is based on the "third wave of sociolinguistics" proposed by Eckert (2005) and Eckert e McConnell-Ginet (2010), who study the relationship between language and social categories, which is considered as non-abstract constructions, pertinent to a "community of specific practice". Our analysis evidenced of the adhesion of Júlio and Marina to the process of changing the Brazilian Portuguese demonstrative system, characterized by the intensification of the use of "esse", especially in endophora. The differences in use between the two letter writers reveal ways in which they engaged as man and woman of their time.
\end{abstract}

Keywords: linguistic variation; genres; community of practice; Social History of Brazilian Portuguese.

\section{Introdução}

No presente trabalho, temos por objetivo o estudo das (inter)relações entre os usos dos pronomes demonstrativos e as questões das identidades dos gêneros "feminino" e "masculino" em textos produzidos por um importante casal da elite brasileira do início do século XX: os Mesquita. Nosso suporte teórico é a chamada "terceira onda da Sociolinguística", por meio da qual procuramos identificar como Júlio de Mesquita Filho e Marina Mesquita se engajavam por meio do uso/prática da linguagem para constituir suas identidades de "homem" e de "mulher" socio-historicamente localizados.

Para realizar tal percurso de pesquisa, partimos dos contornos mais gerais das biografias de Júlio e Marina Mesquita. Em seguida, analisamos um conjunto de cartas trocadas pelo casal, em diversos momentos de suas vidas, mapeando quantitativamente os usos de "este" e de "esse", à luz de estudos linguísticos sobre a mudança no sistema pronominal demonstrativo do Português brasileiro - Mattoso Camara Jr. (1970/2000), Cid, Costa e Oliveira (1986), Pavani (1987), Castilho (1993), Jungbluth (1998), Roncarati (2003), Marine $(2004,2009)$ e Pereira $(2005,2013)$. Para inter-relacionar esses dados linguísticos aos dados sócio-históricos, buscamos compreender os contornos mais gerais do "masculino" e do "feminino" na elite brasileira do período, apoiando-nos em D'Incao (2011) e Hahner (2012). Depois, retornamos às cartas para nelas identificar como nossos missivistas se constituíam como "homem" e "marido" e como "mulher" e "esposa" no interior da família 
que constituíram. Por fim, sugerimos uma interpretação de como poderíamos interrelacionar as práticas da linguagem e as sociais do casal, partindo dos dados levantados ao longo de toda pesquisa.

\section{Estudos sobre os pronomes demonstrativos no português brasileiro}

O uso dos pronomes demonstrativos no Brasil já foi objeto de estudos de importantes pesquisadores. Mattoso Camara Jr. (1970/2000), por exemplo, apontou, a partir de sua observação da fala carioca, que, na função anafórica (ou seja, na endófora), já não haveria mais oposição entre "este" e "esse". Haveria sim uma oposição entre "este"/"esse" versus "aquele", "[...] assinalando o primeiro membro proximidade no contexto e o segundo uma referência à distância" (MATTOSO CAMARA JR, 1970/2000, p. 124). O mesmo fato estaria ocorrendo, no emprego dêitico (ou seja, na exófora), de modo que o sistema pronominal tripartite hoje se apresentaria instável, e, na fala, haveria equivalência gramatical entre "esse" e "este". A razão disso para o linguista estava na proximidade fonológica entre os dois pronomes, levando à situação de variação.

Na década de 1980, os estudos sociolinguísticos passaram a confirmar tais tendências, ao analisar quantitativamente corpora da oralidade. Assim, Cid, Costa e Oliveira (1986) analisaram a fala carioca e constataram um predomínio de "esse" em contexto no uso endofórico, atingindo 89\% de produtividade. Pavani (1987), por sua vez, analisando o material do NURC/SP, constatou que, na fala culta paulistana, a forma "esse" representava $63,5 \%$ dos usos, sendo que as relações apontadas pelas gramáticas normativas entre os locativos e os demonstrativos ("este"/"aqui" e "esse"/"aí") não se mostravam mais rígidas, sendo comum a combinação de "esse" com "aqui".

Mais tarde, na década de 1990, Castilho (1993) encontrou uma menor frequência de "este" na oralidade. Em seus dados, as formas de "esse" atingiram 58\% do total. Para as formas neutras, a frequência de "isso" chegaria a 67\% dos casos. Já Jungbluth (1998) mostrou que gêneros escritos podem favorecer ainda as formas de "este", em estudo baseado em folhetos de poesia de cordel.

Roncarati (2003), analisando dados da fala carioca, também confirmou a reconfiguração do sistema mostrativo de primeira e segunda pessoa. Isso estaria favorecendo a implementação de um sistema dicotômico naquela variedade, dada ao inexpressivo uso das formas "este/isto", tanto ao nível do indivíduo quanto de toda a comunidade.

Já Marine (2004) comparou o uso dos demonstrativos em anúncios publicados na imprensa do século XIX, ao uso feito nas "seções livres" da imprensa publicada entre 1901 a 1915, e, por fim, a dados extraídos de revistas femininas em dois períodos (as décadas de 1960-70 e a década de 1990). A pesquisa sugeriu que o processo de mudança no 
Brasil seria um caso de "especialização de formas", em que "esse" seria, por excelência, a forma para a endófora, enquanto "este" teria se especializado na exofóra (MARINE, 2004, p. 120).

Pereira (2005) realizou a comparação de materiais do Português brasileiro e do Europeu, mais uma vez contrastando o uso de "este" e de "esse". Trabalhando com filmes, textos de notícias escritas publicadas na imprensa e com romances traduzidos a partir do inglês - uma língua com sistema demonstrativo binário -, a pesquisa revelou uma elevada produtividade das formas de "esse" na endófora. A forma de "este" só seria recuperada em textos como os romances traduzidos, mais suscetíveis aos processos de revisão e correção textual. A sobrevivência de "este" se manteria apenas por imposição de uma norma prescrita, de modo que o quadro deveria ser caracterizado como um processo de substituição ainda não finalizado.

Marine (2009) também comparou o uso brasileiro ao lusitano, avaliando o corpus cartas de leitoras publicadas em revistas femininas. Dessa vez, seus dados comprovaram o uso predominante das formas de "esse" e "isso" no uso endofórico. Para a deixis, a baixa quantidade de dados fornecidos pelo material não permitiu a ratificação da tese da "especialização de formas".

Por fim, Pereira (2013) realizou um estudo dos demonstrativos, em perspectiva diacrônica, usando como corpus filmes brasileiros produzidos em dois períodos: as décadas de 1950/60 e os anos 1990/2000. No uso geral, o trabalho mostrou o movimento de ampliação da forma "esse", que partiu de $79 \%$ de frequência para atingir $96 \%$ na virada do século XXI. Na exófora, a produtividade das formas de "este" nos filmes reduziu-se de $26 \%$ para $5 \%$ dos casos. Em função endofórica, o material mostrou que as formas de "esse" sempre foram as mais utilizadas, respondendo por $97 \%$ das ocorrências.

Se de fato o sistema de pronomes demonstrativos se transformou ao longo do século XX, como Júlio e Marina Mesquita se portaram diante dessa mudança gramatical? Será que podemos relacionar as escolhas desses indivíduos por "este" ou "esse" às suas práticas socioculturais, em especial, no engajamento como "homem" e "mulher" de seu tempo? Essas são as questões que perseguiremos nas próximas seções. Antes, no entanto, cumpre-se discorrer sobre diferentes trabalhos que relacionaram usos linguísticos e gênero. É o que faremos na seção a seguir.

\section{A pesquisa linguística e o tratamento da (inter)relação entre linguagem e gêneros}

A relação entre o gênero e o uso da linguagem foi objeto de análise de muitos trabalhos. Gauchat (1905 apud LABOV, 2008), estudando o dialeto Charmey no nível fonético, 
sugeriu que as mulheres usavam mais formas inovadoras do que os homens, argumento reforçado por exemplos de história do Francês em que as mudanças linguísticas haviam sido iniciadas por elas.

Labov (2008), discutindo o trabalho de Guachat (1905), em seção sobre o papel das mulheres na variabilidade linguística, afirma ter encontrado resultados semelhantes que indicavam a opção das mulheres por formas inovadoras, principalmente nos momentos de fala marcados por um maior monitoramento. O autor questiona então os motivos desse comportamento feminino, procurando discutir possíveis respostas a isso.

Nossas respostas no momento não passam de especulações, mas é óbvio que tal comportamento das mulheres deve desempenhar um importante papel no mecanismo da mudança linguística. Na medida em que os pais influenciaram a língua inicial das crianças, as mulheres certamente conversam mais do que os homens com as criancinhas e têm uma influência mais direta durante os anos em que as crianças estão formando regras linguísticas com maior rapidez e eficiência. Parece provável que o ritmo do progresso e a direção da mudança linguística devem muito à especial sensibilidade das mulheres a todo o processo. (LABOV, 2008, p. 346).

Labov, entretanto, afirma que seria equivocado sustentar a posição generalizante sobre as mulheres nas inovações. Baseando-se em seu importante estudo sobre a centralização de /ay/ e /aw/ em Martha's Vineyard, e em Trudgill (1971 apud LABOV, 2008), o autor aponta a possibilidade de homens também assumirem a liderança no processo de mudança em relação às mulheres. E com isso, corrige a interpretação em outros termos: "A generalização correta, então, não é a de que as mulheres lideram a mudança linguística, mas sim que a diferenciação sexual da fala frequentemente desempenha um papel importante no mecanismo da evolução linguística" (LABOV, 2008, p. 348). E acrescenta uma proposta importante para entendimento da questão:

A diferenciação sexual com que estamos lidando depende claramente de padrões de interação social na vida diária. [...] A diferenciação sexual dos falantes não é, portanto, somente um produto de fatores físicos, ou de diferentes quantidades de informação referencial fornecida por eles, mas, sim, uma postura expressiva que é socialmente mais apropriada para um sexo do que para outro. (LABOV, 2008, p. 348).

Paiva (2010) faz um painel bem completo sobre a questão em pesquisas sociolinguísticas realizadas, incluindo as que tomaram o português do Brasil como corpus de análise. A autora já na abertura do texto afirma a impossibilidade de fechar os olhos ao fato de que 
[...] a maior ou a menor ocorrência de certas variantes, principalmente daquelas que envolvem o binômio forma padrão/forma não padrão e o processo de implementação de mudanças estejam associados ao gênero/sexo do falante e à forma de construção social dos papéis feminino e masculino. (PAIVA, 2010, p. 33).

A autora retoma Fischer (1958 apud PAIVA, 2010) que, estudando a fala de crianças em uma pequena comunidade, associou o uso do morfema final dos verbos em inglês '-ing' às garotas, enquanto os garotos, por sua vez, preferiam a forma não prestigiada "-in". Segundo a autora, outros estudos mostraram "um padrão bastante regular em que as mulheres demonstram maior preferência pelas variantes linguísticas mais prestigiadas socialmente". Haveria uma maior consciência feminina acerca do "status social das formas linguística" (PAIVA, 2010, p. 35).

Mas os estudos que pretendem mostrar a relação entre gênero e variação linguística devem estudar, segundo a autora, não somente as formas linguísticas prestigiadas, mas também a organização social da comunidade de fala. Comunidades diferentes das que encontramos no ocidente podem apresentar uma configuração distinta, como mostra Haeri (1987 apud PAIVA, 2010, p. 35).

Paiva lembra que, conforme mostram os estudos de Tannen (1990) e Couthard (1991), as mulheres, diferentemente dos homens, parecem orientar suas conversações de uma forma mais solidária (apud PAIVA, 2010, p. 35). Além disso, a pesquisadora lembra que a variável gênero/sexo interage com outras variáveis, como classe social, estilo de fala, faixa etária, escolarização, mercado ocupacional, etc.

A complexidade da relação entre a linguagem e a questão do gênero pode ser percebida em Lopes et al. (2006) que trabalharam com cartas dos Otonni, família da elite fluminense do século XIX. Nesse trabalho, dentre outros fenômenos, os autores avaliam a questão do uso da variação de "você" e "tu", da posição dos clíticos e das formas verbais que expressam futuro, opondo o uso de Christiano Ottoni ao de Bárbara, sua esposa. A análise mostrou que Bárbara fazia um uso generalizado de "você", optava invariavelmente pela próclise com verbos de lexias simples, mas preferia expressar o futuro com a forma do futuro do presente, nunca usando perífrases de ir/vir. Já seu marido, ao contrário, preferia o uso de "tu", fazia um uso equilibrado entre a próclise e a ênclise com verbos simples e, embora fizesse uso mais intenso de futuro do presente e de perífrase com "haver", já produzia sentenças com "ir/vir". Tais resultados evidenciariam o que consideram "[...] contradições inerentes à pressão das inovações frente à força de retração peculiares aos fenômenos de variação e mudança, pois aqui e ali vemos reflexos de um passado distante e de um futuro próximo" (LOPES et al., 2006, p. 811).

Sem desconsiderar a importância dos trabalhos que mencionamos nos parágrafos anteriores, parece-nos bem relevante colocar aqui a proposta de Eckert (2005) e 
Eckert e McConnell-Ginet (2010) para o estudo da relação entre variáveis sociais e uso da linguagem, a qual assumimos integralmente. Esses trabalhos criticam o uso de noções como "homens" e "mulheres" como conceitos pressupostos e preestabelecidos, sugerindo que a literatura sociocientífica produzida até hoje deva ser lida com cuidado, já que refletiriam conclusões obtidas com populações diferentes, em temporalidades e circunstâncias distintas. Eckert e McConnell-Ginet (2010) não sugerem que se ignorem tais caracterizações abstratas de identidade e de gênero, mas que nos responsabilizemos pela ligação de cada uma dessas abstrações com uma ampla gama de práticas linguísticas e sociais que possibilite o exame das especificidades de sua realização concreta em comunidades reais. Deslocam, então, a questão de uma comunidade de fala geograficamente situada, resultado direto de uma classificação abstrata, para uma "comunidade de prática", assim entendida, na qual o social é também construção².

Uma comunidade de prática é um agregado de pessoas que se reúnem regularmente para se engajar em alguma ação (em grande escala). Uma família, uma sala de aula de linguística, uma banda de garagem, companheiros de quarto, um time de esportes, até uma pequena aldeia. No curso de seu engajamento, a comunidade de prática desenvolve maneiras de fazer as coisas - práticas. E essas práticas envolvem a construção de uma orientação compartilhada para o mundo ao seu redor - uma definição tácita de si mesmas em relação umas às outras e em relação a outras comunidades de prática. (ECKERT, 2005, p. 16, tradução nossa3).

Esse tratamento

[...] retira da noção de comunidade sua caracterização em termos de localização ou população e define uma comunidade por seu engajamento social - afinal de contas a linguagem serve a esse engajamento -, e não ao lugar ou às pessoas como uma coleção de indivíduos. (ECKERT; MCCONNELL-GINET, 2010, p. 95).

A língua, então, imbrica-se com outros sistemas simbólicos vigentes, permitindo que em tais "comunidades de prática" possamos exercitar a constante ação de significar

20 conceito de "comunidade de prática" é emprestado em Eckert (2005) e Eckert e McConell-Ginet (2010) de Wenger (1990 apud ECKERT; MCCONNELL-GINET, 2010) e Lave e Wenger (1991 apud ECKERT; MCCONNELL-GINET, 2010).

3 No original: "A community of practice is an aggregate of people who come together on a regular basis to engage in some enterprise (writ large). A family, a linguistics class, a garage band, roommates, a sports team, even a small village. In the course of their engagement, the community of practice develops ways of doing things - practices. And these practices involve the construction of a shared orientation to the world around them - a tacit definition of themselves in relation to each other, and in relation to other communities of practice". 
nós mesmos e aos outros, em processo de mútua interação entre o linguístico e o sociocultural. E é a partir daí que o "feminino" e o "masculino" se constituem.

A questão, por conseguinte, não se resume em associar um determinado uso às mulheres, mas passa certamente por pensar sobre qual "feminino" estamos falando e como ele emerge no interior de uma dada comunidade de prática a partir do engajamento dos indivíduos. Nosso trabalho procurou perseguir esse modo de pensar as interações entre gênero e linguagem.

\section{Questões metodológicas}

O corpus que propomos para o trabalho de pesquisa é resultante da troca de correspondência entre Júlio de Mesquita Filho e sua esposa, Marina Mesquita. As cartas que analisamos cobrem períodos importantes desses dois membros da família Mesquita, nos quais estiveram separados em função do conflito no âmbito da chamada "Revolução de 1932", em razão da prisão de Júlio, e, ainda, em função dos seus dois exílios nos anos subsequentes. São textos produzidos, portanto, nas décadas de 1930 e 1940.

O nosso acesso às cartas foi facilitado por sua organização e publicação em livro, por um dos netos do casal, Ruy Mesquita Filho, em 2006. Segundo o editor, com quem obtivemos contato diretamente por mensagem de e-mail, à época do lançamento da obra, optou-se apenas pela atualização ortográfica, não tendo havido qualquer outra alteração textual.

Para a presente pesquisa, analisamos 83 cartas e mensagens, sendo que em 69 delas encontramos usos de pronomes demonstrativos. Dessas, 39 foram escritas por Marina Mesquita e 30 têm a autoria de Júlio de Mesquita Filho. Com este material, fizemos uma análise quantitativa das ocorrências de "este" e "esse", analisando-as nos contextos de endófora e de exófora.

Buscamos no texto também elementos discursivos que evidenciassem mais as relações estabelecidas entre os dois esposos de afetividade e proximidade. Em especial nos interessava saber como as identidades de gênero "masculino" e "feminino" foram constituídas nas cartas. Assim procuramos trechos das cartas que nos permitissem dar resposta às seguintes questões: a) Quais as funções que cada missivista assume em relação à família por eles constituída em questões como cuidado dos filhos, problemas do lar, alimentação, cuidado com os negócios da família, etc.?; b) Quais as marcas de afetividade e de proximidade que um expressa pelo outro através da linguagem?; e c) Como cada um se define diante dos fatos vividos e, em especial, diante da separação geográfica imposta pelo exílio de Júlio?

Antes de passarmos à análise dos dados, é necessário começar a reconstituir um pouco das biografias dos dois personagens, autores das cartas, que analisamos. 


\section{Quem eram os Mesquita?}

Júlio de Mesquita Filho era filho de Júlio Mesquita, este último também brasileiro. Sua família, que era de origem portuguesa, havia se transferido para o Brasil no início do século XIX, juntamente com a família real portuguesa em 1808. Depois, afixaram-se em Campinas, no interior de São Paulo, sobrevivendo de comércio. Com as transformações em São Paulo ao final do século, sua família se transferiu para a capital do Estado.

Os Mesquita são conhecidos por serem ainda hoje os proprietários do jornal O Estado de S. Paulo. Este veículo de imprensa nasceu nas mãos de Rangel Pestana, ainda no Império, e com o nome de Província de S. Paulo. Júlio Mesquita, o pai, trabalhou como funcionário do jornal de Pestana, tornando-se, em fins da década de 1890, acionista da empresa, inicialmente em sociedade com José Felinto da Silva e, depois, sozinho, já em 1902 (MARCOVITCH, 2006).

Júlio de Mesquita Filho teve uma educação formal bastante sólida. O curso primário foi realizado na cidade de São Paulo. Depois, mais velho, seguiu para a Escola Acadêmica em Lisboa e depois para o Colégio de La Chatelaine, na Suíça. Em 1911, de volta ao Brasil, ingressou na Faculdade de Direito do Largo do São Francisco (MESQUITA FILHO, 2006).

Em 1915, antes de concluir esse curso, já atuava no Estadinho, a versão noturna de O Estado de São Paulo. Foi só com a morte do pai, em 1927, que Júlio de Mesquita Filho assumiu a direção de O Estado de São Paulo (MESQUITA FILHO, 2006).

Sua atuação política foi intensa. Em 1926, ajudou a fundar o Partido Democrático, formado de uma das dissidências do partido Republicano, e que defendia reformas como o voto secreto. Passou a se envolver com o movimento dos tenentistas que desembocaria na tomada do poder por Getúlio Vargas, em 1930. Mais adiante, descontente com os caminhos tomados por Vargas, passou a organizar o movimento paulista que desembocaria na chamada "Revolução de 1932", lutando no front da guerra. Preso, vai duas vezes para o exílio, a última vez no "Estado Novo". Somente a partir de 1943, conseguiu novamente fixar-se em São Paulo, retomando a propriedade do jornal. Faleceu em 1969 (MESQUITA FILHO, 2006).

Se de Júlio de Mesquita Filho é fácil obter elementos para compor sua rápida biografia, de Marina, sabe-se bem menos. Marina Vieira de Carvalho Mesquita era filha do Dr. Arnaldo Vieira de Carvalho, fundador da Faculdade de Medicina e de instituições hospitalares ainda hoje relevantes, como o Instituto do Câncer. O Dr. Arnaldo, como era conhecido, nasceu em Campinas, mas sua família teria vindo de Santos, sempre formada por homens com atuação política relevante (MESQUITA FILHO, 2006). 
A formação formal de Marina se deu fora do ambiente escolar, ou seja, em casa com professores particulares, o que não era incomum para os filhos da elite da época, e em especial, para as meninas (MARCÍLIO, 2005). Essa educação não resultou em pouco conhecimento cultural. Aprendeu não somente a escrever e ler em língua materna, mas também passou a dominar o francês, e por fim, o espanhol. Tinha, ainda, alguns conhecimentos de inglês. Ela se casou com Júlio de Mesquita Filho em 1926 e o casal teve três filhos. Atuou também em obras de caridade, sendo presidente da Associação Santa Terezinha, que cuidava dos filhos de hansenianos. No primeiro exílio do marido, foi com os filhos encontrar-se com ele na Europa, morando em Lisboa por um ano. No segundo exílio, deixou seus filhos com sua irmã, e seguiu o marido até o retorno para o Brasil, em 1943, quando se estabeleceram novamente na cidade de São Paulo. Faleceu em fevereiro de 1975 (MESQUITA FILHO, 2006).

Agora que já conhecemos nossos missivistas, podemos apresentar o uso linguístico que eles fizeram na questão dos demonstrativos, o que faremos a seguir.

\section{0 que a análise estritamente linguística das cartas nos conta}

As cartas dos Mesquita confirmam a tendência mais geral da mudança linguística dos pronomes demonstrativos no Português brasileiro. A Tabela 1, a seguir, evidencia que, considerando a totalidade dos usos, as formas de "esse" já se mostraram mais produtivas que a de "este", respondendo por 58\% das ocorrências que encontramos, na totalidade dos usos feitos pelos Mesquita.

Tabela 1. Demonstrativos em uso pela Família Mesquita

\begin{tabular}{c|c|c|c|c|c|c}
\hline \multirow{2}{*}{ Pronome } & \multicolumn{2}{|c|}{ Endofórico } & \multicolumn{2}{c|}{ Exofórico } & \multicolumn{2}{c}{ Total } \\
\cline { 2 - 7 } & Qtd. & $\%$ & Qtd. & $\%$ & Qtd. & $\%$ \\
\hline ESSE & 140 & $72 \%$ & 5 & $9 \%$ & 145 & $58 \%$ \\
\hline ESTE & 55 & $28 \%$ & 52 & $91 \%$ & 107 & $42 \%$ \\
\hline Total & 195 & $100 \%$ & 57 & $100 \%$ & 252 & $100 \%$ \\
\hline
\end{tabular}

Fonte: Elaboração própria

A tabela 1, acima, evidencia também a resistência de "este" nas referências exofóricas, contexto no qual $91 \%$ dos usos são realizados com essa forma. Estes dados confirmam a argumentação de Pereira (2005) de que o processo de substituição "em andamento" no português brasileiro se iniciou com a referência endofórica e, somente mais tarde, atingiu a exófora. 
Realizada essa rápida análise do uso dos pronomes demonstrativos nas cartas dos Mesquita, podemos, então, verificar se há diferenças entre Marina e Júlio. A tabela 2 , adiante, pode colaborar nessa comparação. Vejamos seus dados:

Tabela 2. Demonstrativos em uso pela Família Mesquita

\begin{tabular}{c|c|c|c|c|c|c|c|c|c|c|c|c}
\hline Forma & \multicolumn{4}{|c|}{ Uso de Marina } & \multicolumn{5}{c}{ Uso de Júlio } \\
\hline & Endofórico & Exofórico & \multicolumn{2}{|c|}{ Total } & \multicolumn{2}{c}{ Endofórico } & \multicolumn{2}{c}{ Exofórico } & \multicolumn{2}{c}{ Total } \\
\hline & Qtd. & $\%$ & Qtd. & $\%$ & Qtd. & $\%$ & Qtd. & $\%$ & Qtd. & $\%$ & Qtd. & $\%$ \\
\hline ESSE & 101 & $76 \%$ & 3 & $10 \%$ & 104 & $63 \%$ & 39 & $63 \%$ & 2 & $8 \%$ & 41 & $47 \%$ \\
\hline ESTE & 32 & $24 \%$ & 28 & $90 \%$ & 60 & $37 \%$ & 23 & $37 \%$ & 24 & $92 \%$ & 47 & $53 \%$ \\
\hline Total & 133 & $100 \%$ & 31 & $100 \%$ & 164 & $100 \%$ & 62 & $100 \%$ & 26 & $100 \%$ & 88 & $100 \%$ \\
\hline
\end{tabular}

Fonte: Elaboração própria

O contraste dos dados de Marina e de Júlio, consolidados anteriormente, evidencia que não há qualquer distinção na norma linguística dos dois missivistas quando se veem diante da necessidade de apontar elementos para fora do texto. Tanto um como outro optam pelas formas de "esse" ao menos em $90 \%$ dos usos de suas cartas.

As diferenças surgem de forma explícita na endófora. Nesse contexto, embora ambos se utilizem prioritariamente das formas de "esse" - e com índices de produtividade elevados -, Marina parece ser mais incisiva na escolha dessa forma. Como podemos ver, ela usa "esse" em 76\% das ocorrências que mapeamos, contra 63\% de Júlio. Assim, Marina revelase mais contundente no uso da forma verbal que se tornaria a preferencial no Brasil.

Abaixo, exemplificamos um uso de Júlio e de Marina com a forma de "esse", em contexto de endófora.

(1) Nova York causou-me fortíssima impressão, como realização arquitetônica. [...] Isso tudo, porém, no que diz respeito ao centro propriamente dito.

(2) De vez em quando circulam boatos sobre nova prisão do Armando. Isso nos apavora e pedimos a Deus que ao menos ele seja poupado.

Importante dizer que os dados endofóricos que encontramos são de retomadas textuais. Dos 252 usos de demonstrativos analisados nas cartas dos Mesquita, somente 5 (2 de Marina e 3 de Júlio) são de catáfora. Desse modo, a grande maioria dos dados que analisamos é de anáfora, contexto em que alguns gramáticos, como Cunha e Cintra (2001), deixam a critério do falante a escolha da forma pronominal a ser utilizada e, portanto, configura-se como relativamente mais livre de pressões prescritivas. 
Os dados que encontramos para os Mesquita poderiam sugerir relações diretas entre o uso linguístico e a questão do gênero sexual. Poderiam ser interpretados como mais um indício de que as mulheres - aqui representadas por Marina - colocam-se à frente das mudanças linguísticas. Como não há estigmas, teríamos aqui campo fértil para que essa liderança pudesse ser exercida de maneira plena por Marina Mesquita.

Entretanto, como já deve ter ficado claro na seção que expusemos nosso enquadre teórico, em especial sobre a forma como entendemos as interações entre os usos da linguagem e as categorias sociais (como o gênero), optamos por não aceitar essa conclusão, que em nosso entendimento, seria tão fácil como simplificadora. É preciso compreender melhor o contexto de uso e, mais ainda, avaliar como o "feminino" e o "masculino" foram constituídos por Júlio e Marina. É o que faremos a seguir.

\section{Mas qual feminino? Qual masculino? - 0 que os estudos sobre homens e mulheres da elite da primeira metade do século XX nos contam}

O século XIX é apontado como ponto de mudança - evidentemente gradual - nas relações estabelecidas nas famílias das elites brasileiras, em especial, entre maridos e esposas e filhos. Esse fenômeno, que atingiu as grandes cidades de então - chegando a São Paulo, a cidade dos Mesquita, apenas com as transformações urbanas, sociais e econômicas na passagem do século XIX ao XX - se deu em função da ascensão da burguesia e, portanto, de uma nova mentalidade - burguesa - que reorganizou as vivências familiares e domésticas, alterando o que se entendia por "feminino".

Presenciamos [...] o nascimento de uma nova mulher nas relações da chamada família burguesa. Um sólido ambiente familiar, o lar acolhedor, filhos educados e esposa dedicada ao marido, às crianças e desobrigada de qualquer trabalho produtivo representavam o ideal de retidão e probidade, um tesouro social imprescindível. Verdadeiros emblemas desse mundo relativamente fechado, a boa reputação financeira e a articulação com a parentela como forma de proteção ao mundo externo também marcaram o processo de urbanização do país. (D'INCAO, 2011, p. 223).

E é exatamente aí, nesses espaços públicos da residência burguesa que as mulheres de classe alta ganharam a possibilidade de movimentar-se e de cultivar laços sociais, em situação de aparente liberdade, mas não isentos de sanções. Nesses espaços, seu comportamento passava pelo crivo da rígida apreciação pública. Assim, se as mulheres burguesas passaram a lidar com um código de controle comportamental relativamente mais livre da figura do pai (ou do marido), estavam sujeitas às censuras do grupo social com que essas conviviam, o que era complementado por mecanismos de autocensura provindos de sua educação (D'INCAO, 2011). 
Nesse período, o casamento das famílias burguesas e ricas mantinha a função de garantir um degrau a mais de ascensão social. Mas, a partir de então, às mulheres cabia "contribuir para o projeto familiar de mobilidade social através de sua postura nos salões como anfitriãs e na vida cotidiana, em geral, como esposas modelares e boas mães" (D'INCAO, 2011, p. 229). Nessa lógica, os casamentos arranjados persistiam, mas o "amor romântico" passou a ganhar algum espaço nos lares burgueses.

No fim do século $X X$, poucas mulheres de classe alta pareciam admitir que os pais pudessem "arranjar" casamentos sem consultar a noiva. Havia, então, espaço para o amor romântico e o sentimento no matrimônio e as convenções do namoro e do casamento arranjado podiam se misturar (HAHNER, 2012).

Outra função importante que a mulher da elite ganhou, a partir desse processo, diz respeito à maternidade e à criação dos filhos. A mãe passa a ser responsável por supervisionar e garantir a primeira educação dos filhos, deixando para trás o modelo calcado na grande influência de amas e de elementos estranhos à família (D'INCAO, 2011).

Evidentemente, não faziam o serviço pesado doméstico, mas contavam com o trabalho de criadas, que, a partir de 1870, passaram a ser cada vez realizado por mulheres pobres livres que residiam com a família e com quem as senhoras burguesas estabeleciam uma relação marcada por conflitos (HAHNER, 2012).

Marina e Júlio cresceram convivendo com tais construções sociais acerca dos papéis que o homem e a mulher deviam exercer na sociedade e no interior de uma família. No diálogo que o indivíduo estabelece com o social, eles, certamente, se constituíram a partir de tais construções, afastando-se às vezes mais, às vezes menos, dos modelos praticados pelo grupo social ao qual pertenciam. Para buscar pistas sobre isso, podemos analisar o conteúdo das cartas que eles escreveram. É o que apresentamos na próxima seção.

\section{Mas qual feminino? Qual masculino? - 0 que nossos missivistas nos contam em suas cartas}

Nesta seção, buscamos sintetizar o que as cartas contam sobre Júlio e Marina e as formas como as construções de "feminino" e de "masculino" são projetadas pelos missivistas em suas correspondências. Para tanto, optamos por estabelecer alguns contrastes entre Marina e Júlio que nos parecem fundamentais.

O primeiro contraste que gostaríamos de assinalar diz respeito à forma como os dois missivistas expressam uma relação de afetividade pelo outro através da linguagem. Marina usa e abusa do humor e da informalidade, em uma estratégia que busca 
claramente fortalecer os laços entre os dois, separados fisicamente. Podemos ver isso, por exemplo, nas expressões usadas nas etapas de despedida de suas mensagens. É o que podemos ver nos excertos abaixo:

(3) Até breve. Beijos e abraços do Ruy e de sua velha cacete. Marina. (Carta de Marina para Júlio, datada de 01/07/1933).

(4) Se Deus nos ajudar, não terei tempo de escrever muitas. Quando comprarmos passagens, telegrafo avisando. Até lá, receba beijos em penca da criançada e da sua Marina, que não se aguenta mais de saudade. (Carta de Marina para Júlio, datada de 11/11/1932).

Em (3) Marina Mesquita se autodenomina "sua velha cacete"; enquanto em (4) não manda apenas beijos, mas "beijos em penca". Esse tipo de liberdade de escrita e de uso de expressões carregadas de humor é bem típico dos textos enviados por Marina a Júlio. Estamos diante de uma mulher que busca se aproximar do marido, tão distante e que tanto Ihe faz falta. Ademais, parece ter a função de dar leveza à situação que vivem, trazendo para a interação estabelecida uma certa positividade e otimismo.

Já Júlio, quase sempre se despede de modo protocolar. A fórmula usada no excerto (5), a seguir, evidencia isso. O uso de seu nome no diminutivo aparece em outras correspondências enviadas a amigos e conhecidos, justificando-se por ser homônimo de seu pai, Júlio Mesquita, e não por uma ação intencional de expressar maior afetividade à sua esposa.

(5) Até logo, com um beijo do seu Julinho. (Carta de Júlio para Marina, sem data, provavelmente de 1932).

O contraste da escrita de Marina e de Júlio, em nossa interpretação, parece evidenciar que havia certas sanções para o homem na expressão de intimidade no interior de um casamento. À mulher era permitido expor seus "sentimentos", evidenciando estratégias discursivas de aproximação com seu amado. Júlio talvez não pudesse lançar mão desse procedimento, o que justifica uma linguagem mais objetiva e formal.

Marina escreve como se fizesse um diário, relatando fatos do dia a dia, evidenciando um movimento que procurava fazer com que seu marido pudesse participar da vida da família. Apresenta sempre muitos detalhes cotidianos, misturados a temas da situação política assistida por ela, como temos no excerto (6). 
(6) Segunda, 8 - Ontem conversou-se muito e os meninos estiveram ultra-animados. 0 Ruy já está indo ao cinema aos domingos. O Juca continua preso por não ter melhorado um ponto nos boletins. Aliás, as escolas aqui vão de mal a pior. O Júlio, de Armando, me disse que a Politécnica está reduzida a última expressão. (Carta de Marina para Júlio, datada de 5 a 11 de maio de 1939).

Já Júlio escreve ou de forma muito concisa, em estilo que mais lembra um bilhete, como podemos ver em (7), ou ainda, por meio de longos textos, que mais parecem ensaios sobre a política do Brasil e do mundo, como podemos ver no excerto (8).

(7) Marina,

A situação continua a mesma: prontidão etc. Chegou mais um preso. Desta vez um oficial do Exército, tenente Lins, de Caçapava. Passamos - eu e o Guimarães - a tarde no campo de futebol. Banquei o juiz! Do seu Julinho (Carta de Júlio para Marina, sem data, provavelmente de 1932).

(8) Voltando atrás. Deixei Paris sob uma atmosfera sinistra. Todos certos de que era inevitável a guerra e convencidos de que pouca coisa restaria da Europa, depois do furacão. As despedidas foram tristíssimas. Os moços, em idade militar, esperavam verme ainda, se não morressem na luta, e os velhos vivem na perspectiva de assistir a partida dos moços e a destruição de tudo quanto os séculos acumularam de belo e de grande. (Carta de Júlio para Marina, datada de 6 de maio de 1939).

O certo é que, em ambas as estratégias, Júlio mantém uma distância relativa de sua esposa e de seus filhos, tratando a maior parte das vezes de assuntos que não dizem respeito ao relacionamento amoroso e aos fatos cotidianos de sua família. Sua escrita parece evitar que tenha de priorizar o amor de Marina e de seus filhos, favorecendo como tema os seus atos e sua luta pelo mundo ideal que persegue.

Marina, enquanto pôde, era, ao que parece, responsável por cuidar do esposo, em questões como sua melhor alimentação, ainda que estivesse no campo de batalha ou nas prisões. Assim, enquanto ela se preocupa em fornecer alimentos para o marido que está no front de batalha como em (9), Júlio pede que prepare o almoço - dele e de seus companheiros - enquanto está preso em São Paulo, após a derrocada dos paulistas, como vemos em (10).

(9) Não quer mais alguma coisa? Comida, bolachas, doces, queijo. (Carta de Marina para Júlio, de 18/07/1932). 
(10) Os oficiais estão pedindo cuscuz para amanhã. A prontidão obriga a oficialidade toda a permanecer aqui, o que eleva a dez o número dos candidatos ao almoço. Conto com você, pois garanti que o cuscuz estaria aqui às doze e meia sem falta. (Carta de Júlio para Marina, sem data, do IV Esquadrão de Cavalaria, Ibirapuera).

Ela, como mulher da elite de seu tempo, permanece com o encargo de cuidar dos três filhos do casal. A educação, a formação, a alimentação, a saúde e outras questões acerca de seus filhos estão todas sob sua responsabilidade. É ela quem deve, por exemplo, cuidar do filho Ruy, a quem dispende esforços no tratamento das limitações físicas resultantes de paralisia infantil, como podemos observar em (11). A Júlio, distante, cabe apenas fazer perguntas breves sobre o estado e a saúde de seus filhos, geralmente no encerramento de suas correspondências, como o faz no excerto (12).

(11) O Ruy já veio com a botina nova ainda por acabar para experiência. A diferença de cumprimento de perna persiste. Penso que por isso o Putti mandou que fizesse distensão persistente do joelho. Para isso fomos ontem à sala de ginástica. Felizmente a tal da distensão não dói. (Carta de Marina para Júlio, datada de 30/05/1933).

(12) Abrace e beije um milhão de vezes os nossos filhinhos e receba um grande, um infinito abraço do seu Julinho. (Carta de Júlio para Marina, datada de 30/10/1932).

Indícios do distanciamento de Júlio para com seus filhos talvez possam ser percebidos em um fato simples que constatamos em carta de Marina quando o marido estava em seu primeiro exílio. Nessa carta, Marina corrige um erro que Júlio teria cometido quando enviou um telegrama a seu filho, equivocando-se quanto a sua data de aniversário. Ainda que o gesto demonstre preocupação com fatos da vida do filho e que, aparentemente, tenha sido carregado de afetividade, o equívoco, em nossa interpretação, sugere seu distanciamento ou, pelo menos, certa desconexão em relação ao cotidiano de família.

(13) A família passa bem. A criançada forte, toda fazendo exame. Estão desesperados para marcarmos a partida. O Júlio [filho do casal] recebeu ontem seu telegrama. Você se enganou, ele faz anos em dezembro. Ficou como sempre comovidíssimo com o dito. (Carta de Marina para Júlio, datada de 14/11/1932).

Mas as funções de Marina no arranjo matrimonial com Júlio não se limitam aos cuidados dos filhos e do marido. A ausência de Júlio faz com que ela tenha que se preocupar e se responsabilizar por decisões acerca de questões financeiras e de patrimônio, muito embora em nenhum momento tenha assumido a direção da empresa jornalística que possuíam. É o que podemos ver abaixo, no excerto (14), no qual a vemos decidindo sobre o aluguel da residência dos Mesquita, e em (15), que mostra um marido exilado e dependente da remessa de recursos para o seu sustento pela esposa. 
(14) Aluguei hoje nossa casa ao João Sampaio. Creio que fiz um bom negócio. Ele compromete-se a pintar toda a casa e fazer várias reforminhas, toma a casa sem móveis e por três anos pagando o primeiro ano 1:200 e os outros dois 1:000. Diz ele que vai conservar nossa casa. (Carta de Marina para Júlio, datada de 11/11/1932).

(15) E o dinheiro? Você não disse que ele teria partido daí a $1^{\circ}$ ? Por quem? (Carta de Júlio para Marina, datada de 09/12/1939)

Em nossa interpretação, as cartas parecem sugerir que nossos missivistas encaram de maneira diferente a separação que enfrentam. Júlio talvez estivesse movido a manter-se distante de sua família e de sua esposa porque entende que está em uma luta marcada por um ideal maior. Já Marina aceita a mobilização do marido, trabalha por mantê-lo em suas batalhas - costurando fardas, cedendo sua própria aliança para levantar fundos aos revolucionários, cuidando para que nada lhe falte, etc. - mas deixa sempre claro que "mudar o mundo" não está entre seus sonhos. Os excertos a seguir, aparentemente, mostram esse contraste.

(16) Mais curioso ainda é que todo esse tempo de vida em comum não haja provocado em você nenhuma modificação na sua maneira de ver e encarar a vida e o mundo. Hoje, como no dia em que nos casamos, você continua inabalável nas suas convicções de um patriarcalismo estreito e renitente, para o qual o universo cabe dentro do círculo da família e todos os espaços que não tenda exclusivamente a melhorar a sorte material dos membros da tribo é um roubo de que são vítimas você como os nossos filhos. Tudo quanto eu possa ter feito pela nossa terra [...] tudo, enfim que constitui e constituiu minha existência, [...] foi e continua a ser esforço, energia e tempo em que eu deixei de empregar na obtenção da felicidade de nossa família. (Carta de Júlio para Marina sem data, provavelmente de 1940).

(17) Sirva a Pátria, mas antes dela lembre-se que você tem três filhos, o Estado e uma mulher cacete que Ihe adora e Ihe manda muitos e muitos beijos. Marina. (carta de Marina para Júlio, datada de 14/07/1932).

Temos aí uma divisão de papéis bastante clara do homem e da mulher no matrimônio vivido por este casal da elite. Enquanto para o homem há a possibilidade de exercer sua liberdade, de correr atrás de ideais - ainda que às custas da distância de sua família, à mulher resta aceitar as decisões do marido e cuidar para que o sonho dele se realize.

Antes de terminar parece-nos relevante apresentar uma das fotos do casal que Mesquita Filho (2006) agregou às cartas que analisamos. Na Figura 1, a seguir, Marina e Júlio aparecem à direita, junto com amigos. Nela podemos ver homens de sorriso mais contido, menos naturais e expressivos que as mulheres que os acompanham. Júlio, assim como em outras imagens reunidas na obra, mostra-se em postura sisuda e inflexível, com mãos à cintura e um rosto sério. 
Figura 1. Um exemplo de figura

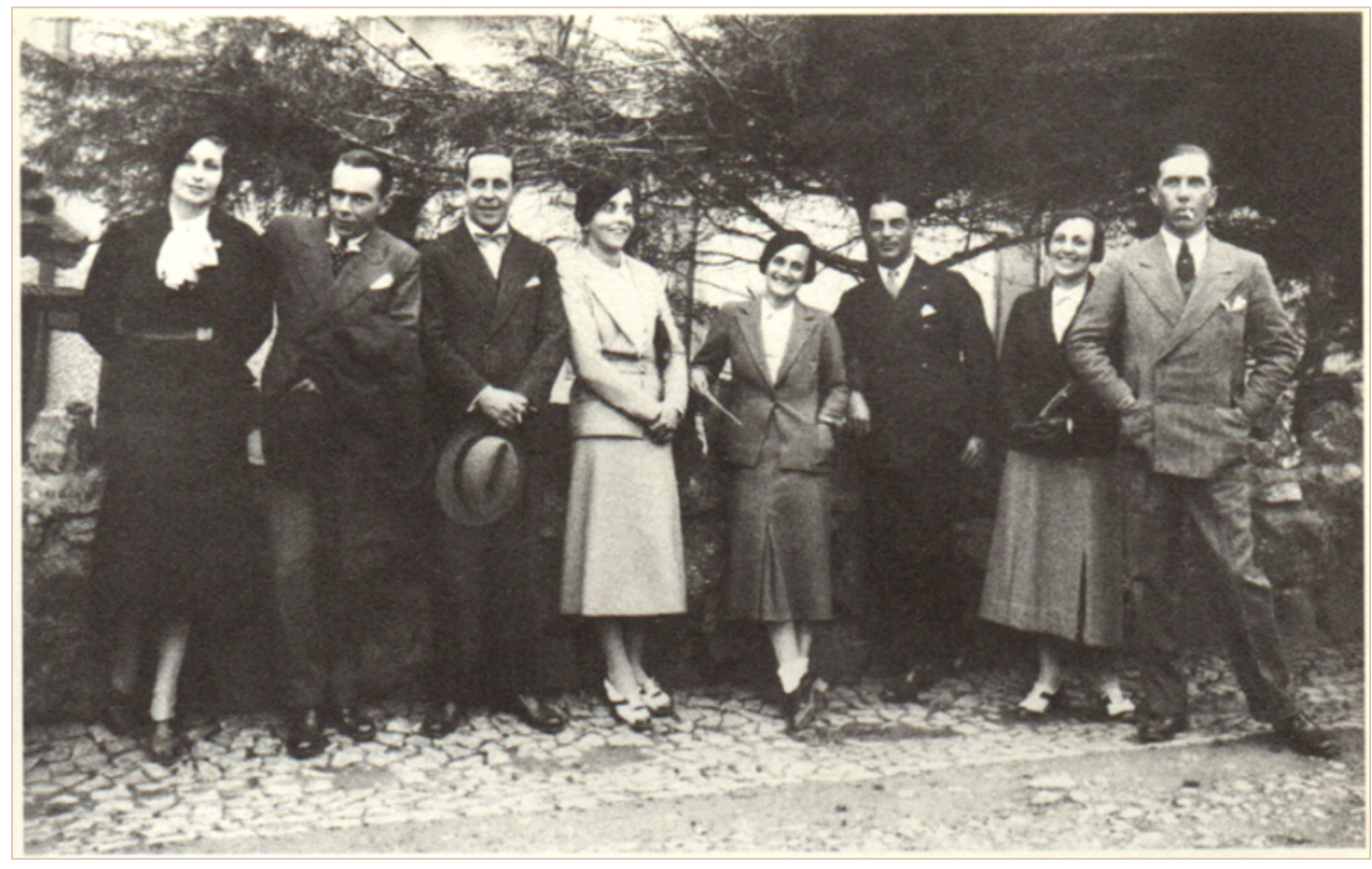

Fonte: Mesquita Filho (2006, p. 53)

Se a interpretação da imagem acima estiver correta, podemos hipotetizar aqui que, em uma comunidade de prática, os engajamentos não se dão apenas pelo uso da linguagem, mas também pelo uso de outros sistemas simbólicos a partir dos quais nos constituímos.

\section{As mútuas interações entre os demonstrativos e o gênero nas cartas dos Mesquita}

As análises que realizamos nas seções anteriores nos levam a sustentar que o protagonismo de Marina na opção pelo uso de "esse" endofórico - ao invés de "este" não é fortuito, nem é prova de que mulheres sempre lideram as inovações linguísticas. Em nossa interpretação, Marina age, através da língua, para produzir e reproduzir um modelo de "feminino", que é a um só tempo individual e social. O uso que faz da língua, em diversos aspectos, e também no caso dos demonstrativos, reflete e viabiliza o seu engajamento em um contorno de mulher de certa elite intelectual de seu tempo que experimenta relativa liberdade no agir, sem, contudo, deixar de flutuar em torno da família e do marido.

O uso preferencial de "esse" endofórico que ela faz é fruto (e, portanto, resultado) de sua formação como mulher. Mas também mostra que no jogo matrimonial parece estar 
mais livre (em relação ao homem) para poder utilizar uma linguagem que favorecesse a aproximação com o outro, para expressar sem filtros os seus sentimentos mais íntimos.

Seu uso também é coerente com a especificidade dos rumos de sua vida, que a colocou diante da tarefa de tomar a frente na tomada de decisões sobre questões patrimoniais e financeiras dos Mesquita, em contexto de ausência do marido. Se é ela quem providencia o aluguel da casa da família ou o envio da "mesada" de Júlio, por que não poderia, inconscientemente, tomar adiante do uso linguístico identificado com uma mudança?

Com o uso mais intenso de "esse" endofórico, Marina não só reproduz uma linguagem feminina própria da comunidade de prática das mulheres de elite que participa, mas também constitui os contornos do "feminino" que vive. O "feminino" de Marina está impregnado em sua própria linguagem, "leve" e "livre", que a permite se aproximar do marido e interagir com o uso de formas mais inovadoras da linguagem, ainda mais se tratando de fenômenos não estigmatizados socialmente.

É, nesse sentido, que entendemos que o quadro sugerido pelas cartas dos Mesquita expõe as mútuas interações entre o uso da linguagem e o sociocultural: o uso linguístico em variação não é mero resultante de uma "variável" social, mas colabora para sua definição, no interior de sua comunidade de prática.

\section{Conclusões}

No presente trabalho, investigamos as interações entre o uso dos demonstrativos e as questões de gênero, em cartas trocadas entre Júlio de Mesquita Filho e Marina Mesquita. Nossa análise linguística evidenciou que o casal já participava nas décadas de 1930 e 1940 do processo de mudança dos demonstrativos com massificação do uso de "esse".

O contexto de endófora nos levou a observar diferenças entre os usos de Júlio e de Marina. Embora ambos tenham optado mais frequentemente pelos usos de "esse", ela fazia um uso mais intenso dessa forma quando comparada ao marido. Nossa análise nos levou a investigar as diferenças de gênero, partindo de um quadro teórico que admite que esses conceitos são produtos construídos socio-historicamente, no interior de uma comunidade de prática. Revisitamos os papéis mais gerais da mulher e do homem no âmbito das famílias e do matrimônio burguês do início do século XX nas grandes cidades urbanizadas e passamos a investigar como o "feminino" e o "masculino" se constituíam nas cartas dos Mesquita para os nossos missivistas.

Nossos resultados nos levam a crer que Marina, por meio da linguagem expressa-se com mais "liberdade" do que Júlio, exatamente por estar relacionada a uma configuração de "feminino", que, em contraposição ao "masculino" de Júlio, pode se permitir a uma maior 
exposição ao seu esposo. A mesma mulher que se arrisca em postura de aproximação em relação ao seu marido pode optar mais intensamente pela forma "esse" no uso endofórico - contexto livre de estigmas, colaborando de modo mais relevante com o processo de mudança do sistema demonstrativo. Se por um lado suas escolhas gramaticais são fruto de sua condição social e individual, são também um dos instrumentos que possui para se engajar no feminino da comunidade de prática a que pertence.

\section{REFERÊNCIAS}

CASTILHO, A. T. de. Os mostrativos no português falado. In: CASTILHO, A. T. de (org.). Gramática do português Falado: as abordagens. v. 3. Campinas: Editora da UNICAMP, 1993.

CID, O.; COSTA, M. C.; OLIVEIRA, C. T. Este e esse na fala culta da Rio de Janeiro. Estudos Linguísticos e Literários, Salvador, n. 5, p. 195-208, dez. 1986.

CUNHA, C.; CINTRA, L. Nova gramática do português contemporâneo. Rio de Janeiro: Fronteira, 2001

D'INCAO, M. A. Mulher e família burguesa. In: PRIORE, M. D. (org.). História das mulheres no Brasil. São Paulo: Contexto, 2011. p. 223-240.

ECKERT, P. Variation, Conventions and Social Meaning. Artigo apresentado ao Annual Meeting of the Linguistic Society of America, 2005. Disponível em https://citeseerx.ist. psu.edu/viewdoc/download?doi=10.1.1.553.1313\&rep=rep1\&type=pdf. Acesso em: 01 dez. 2018.

ECKERT, P.; McCONNELL-GINET, S. Comunidades de prática: lugar onde co-habitam linguagem, gênero e poder. In: OSTERMANN, A. C.; FONTANA, B. (org. e trad.). Linguagem. Gênero. Sexualidade: clássicos traduzidos. Robin Lakoff et al. São Paulo: Parábola, 2010.

JUNGBLUTH, K. O uso dos demonstrativos em textos semi-orais: o caso dos folhetos nordestinos do Brasil. In: GROSSE, S.; ZIMMERMANN, K. (ed.). Substandard e mudança no português do Brasil. Frankfurt: TFM, 1988. p. 329-355.

HAHNER, J. E. Honra e distinção das famílias. In: PINSKY, C. B.; PEDRO, J. M. (org.). Nova História das mulheres no Brasil. São Paulo: Contexto, 2012. p. 43-64.

LABOV, W. Padrões sociolinguísticos. São Paulo: Parábola Editorial, 2008. 
LOPES, C.; MACHADO, A. C.; PAGOTTO, E.; DUARTE, M. E.; CALLOU, D.; OLIVEIRA, J.; ELEUTÉRIO, S.; MARTELOTTA, M. A configuração da norma brasileira no século XIX: análise das cartas pessoais dos avós Ottoni. In: LOBO, T.; RIBEIRO, I.; CARNEIRO, Z.; ALMEIDA, N. (org.). Para História do português brasileiro: novos dados, novas análises. v. VI, Tomo II. Salvador: EdUFBA, 2006. p. 781-815.

MARCÍLIO, M. L. História da escola em São Paulo e no Brasil. São Paulo: Imprensa Oficial do Estado de São Paulo/Instituto Fernand Braudel, 2005.

MARCOVITCH, J. Júlio de Mesquita. In: MARCOVITCH, J. Pioneiros e Empreendedores: a saga do desenvolvimento no Brasil. v. 1. São Paulo: EdUSP, 2006. p. 219-249.

MARINE, T. de C. O binarismo dos pronomes demonstrativos no século XX: este vs. aquele ou esse vs. aquele. 2004. Dissertação (Mestrado em Linguística e Língua Portuguesa) Faculdade de Ciências e Letras, Universidade Estadual Paulista, Araraquara, 2004.

MARINE, T. de C. Um estudo sócio-discursivo do sistema pronominal dos demonstrativos no português Contemporâneo. 2009. Tese (Doutorado em Linguística e Língua Portuguesa)

- Faculdade de Ciências e Letras, Universidade Estadual Paulista "Júlio de Mesquita Filho", Araraquara, 2009.

MATTOSO CAMARA JR, J. Estrutura da língua portuguesa. 32. ed. Petrópolis: Vozes, 1970.

MESQUITA FILHO, R. (org.). Cartas do Exílio: a troca de correspondência entre Marina e Júlio de Mesquita Filho. São Paulo: Editora Terceiro Nome, 2006.

PAIVA, M. da C. de. A. Variável gênero/sexo. In: MOLLICA, M. C.; BRAGA, M. L. (org.). Introdução à Sociolinguística: o tratamento da variação. São Paulo: Contexto, 2010.

PAVANI, S. Os demonstrativos este, esse e aquele no português culto falado em São Paulo. 1987. Dissertação (Mestrado em Linguística) - Instituto de Estudos da Linguagem, Universidade Estadual de Campinas, Campinas, 1987.

PEREIRA, H. B. Esse versus este no português brasileiro e no Europeu. 2005. Dissertação (Mestrado em Filologia e Língua Portuguesa) - Faculdade de Filosofia, Letras e Ciências Humanas, Universidade de São Paulo, São Paulo, 2005.

PEREIRA, H. B. ESSE versus ESTE em filmes brasileiros: substituição ou especialização de formas? Filologia e Linguística Portuguesa, v. 15, p. 83-100, 2013. Disponível em: http://www.revistas.usp.br/flp/article/view/76195. Acesso em: 01 dez. 2018.

RONCARATI, C. Os mostrativos na variedade carioca falada. In: PAIVA, M. da C; DUARTE, M. E. L. (org.). Mudança linguística em tempo real. Rio de Janeiro: Contra Capa, 2003. 